\title{
Solanum surrattence as Potential Corrosion Inhibitor
}

\author{
Manish Kumar Sharma, ${ }^{1}$ Anil Kumar Sharma, ${ }^{2}$ and S. P. Mathur1 \\ ${ }^{1}$ Department of Pure and Applied Chemistry, Maharshi Dayanand Saraswati University, Ajmer 305009, India \\ ${ }^{2}$ Natural Product Laboratory, Department of Chemistry, Rajasthan University, Jaipur 302004, India \\ Correspondence should be addressed to Manish Kumar Sharma, mann_sharma04@yahoo.co.in \\ Received 18 June 2012; Accepted 10 July 2012 \\ Academic Editors: I. Obot and E. Stupnisek-Lisac
}

Copyright ( $) 2012$ Manish Kumar Sharma et al. This is an open access article distributed under the Creative Commons Attribution License, which permits unrestricted use, distribution, and reproduction in any medium, provided the original work is properly cited.

Developping chip and ecofriendlly corrosion inhibitors can replace toxic chemicals which are currently used in industries. Plant extract of Solanum surrattence in acetone, petroleum ether, and methanol has been tasted using mass loss and thermometric measurements for corrosion of aluminium in acid solutions. The plant extract of Solanum surrattence is a good corrosion inhibitor for aluminium. The inhibition efficiency depends upon the concentration of inhibitors, it inhibits the metal of $97.60 \%$ at its maximum value. This inhibitor shows efficiency at $25^{\circ} \mathrm{C}$. At higher temperature the inhibition efficiency decreases. These types of inhibitors can be used to replace the toxic chemicals which are currently used in industries. We find out cheap and ecofriendlly corrosion inhibitors which can be used by acid, petrochemical, and chemical industries.

\section{Introduction}

Aluminium and its alloys lend themselves to many engineering applications because of their combination of lightness with strength, their thermal and electrical conductivities, heat and light reflectivity, and their hygienic and nontoxic qualities. Aluminium and its alloy are exposed to the action of acids in industries; processes in which acid plays a very important role are acid pickling, industrial acid cleaning, cleaning of oil refinery equipment, oil well acidizing, and acid descaling. The corrosion of aluminium and its alloy in acid solutions have extensively been studied [1]. Some chemicals as corrosion inhibitors are currently using in industries to prevent or to reduce the corrosion rates of metals in these acid media. Due to toxic nature and high cost of these chemicals it is necessary to develop environmentally acceptable and less expensive inhibitors. Some natural products have been evaluated as potential corrosion inhibitors for different metals [2]. We have investigated the effect of plant extract of Prosopis cineraria on corrosion of aluminium [3] and mild steel [4] in acid solution in our earlier communications.

The present communication describes the influence of various concentration of the extract of Solanum surrattence on corrosion behavior of aluminium in acid media by mass loss and thermometric measurements.

1.1. Chemical Constituent. The fruit extract of plant yields [5] Solamargine, $\beta$-Solamargine, Cycloartanol, Cycloartenol, and Sitosterol. Leaves and roots extract yields [6] scopoletin, esculin. Fresh berries contain [7] solasurine, 3,4-di hydroxy cinnamic acid, and caffeic acid. Flowers of this plant yields [8] apigenin, quercetin-3-o- $\beta$-D-glucopyranosyl-o- $\beta$ D-mannopyranoside (Figure 1).

1.2. Medicinal Properties [9]. Roots expectorated of Solanum surrattence is useful in cough, asthma, and pain in the chest. Seed are also useful in asthma, and cough. Leaves extract mixed with black pepper is useful in rheumatism. The aqueous and alcoholic extract of Solanum surrattence possesses hypotensive effect which is partly inhibited by atropine. Extract of the herb shows antiviral activity against Ranikhet disease virus and also against sarcoma 180 in mice.

\section{Methodology}

Rectangular specimens of aluminium of dimension $(2.5 \times$ $1.5 \times 0.03) \mathrm{cm}$, containing a small hole of about $3 \mathrm{~mm}$ 


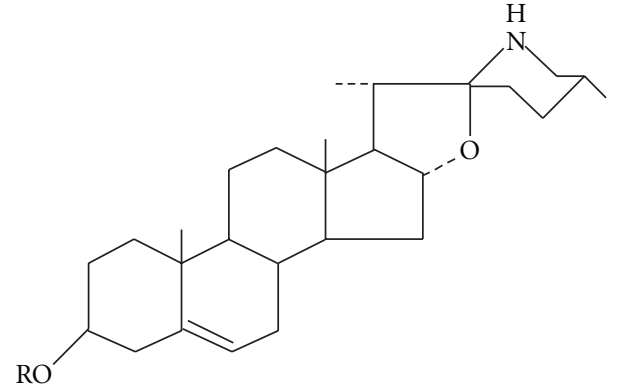

FIGURE 1: Solamargine: $-\mathrm{R}=\alpha$-L-Rha-(1-2Glc)- $\alpha$-L-Rha-(1-4-Glc)$\beta$-D-Glc. $\beta$-Solamargine: $-\mathrm{R}=\alpha$-L-Rha- $\beta$-D-Glc (Figure 2 ).

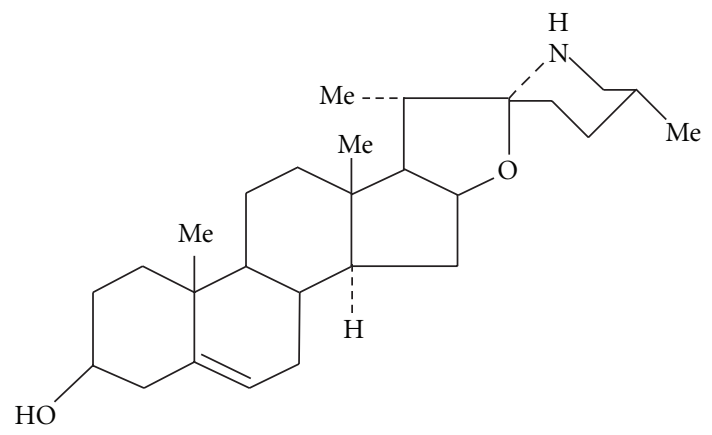

FIgure 2: Solasodine.

diameter near the upper edge were employed for the determination of corrosion rate. Specimens were cleaned by buffing to produce a mirror finish with the help of emery paper and were then degreased. Each specimen was suspended by a glass hook and immersed in a beaker containing $50 \mathrm{~mL}$ of test solution at room temperature and left exposed to air. Evaporation losses were made up with doubly distilled water. After that test specimens were cleaned with benzene, duplicate experiments were performed in each case and mean values of the mass loss were calculated. The acidic solution was prepared by using doubly distilled water. All chemicals used were of analytical reagent quality.

The Solanum extract was obtained by drying, then finely powered and extracted with boiling acetone, petroleum ether, or methanol solvent. The solvent is distilled off and the residue is treated with activated charcoal to remove gunge and pure extract of Solanum was used as probable corrosion inhibitor. [10]

The percentage inhibition efficiency was calculated as

$$
\eta=100 \frac{(\Delta M u-\Delta M i)}{\Delta M u},
$$

where $\Delta M u$ and $\Delta M i$ are the mass loss of the metal in uninhibited and inhibited solution, respectively.

The degree of surface coverage $(\boldsymbol{\theta})$ was calculated as

$$
\theta=\frac{\Delta M u-\Delta M i}{\Delta M u}
$$

where $\theta$ is surface coverage and $\Delta M u$ and $\Delta M i$ are the mass loss of the metal in uninhibited and inhibited acid solution, respectively.

The corrosion rate that is mmpy (mili miles per year) is calculated by the following equation:

$$
\text { Corrosion rate }=\text { Mass loss } \times 87.6
$$

(mmpy) Area $\times$ Time $\times$ Metal density,

where mass loss is expressed in mg, area is expressed in $\mathrm{cm}^{2}$ of metal surface exposed, time is expressed in hours of exposure, metal density is expressed in $\mathrm{gms} / \mathrm{cm}^{3}$, and 87.6 is conversion factor.

Inhibition efficiencies were also determined using a thermometric technique [10]. This involved the immersion of single specimen measuring $(2.5 \times 1.5 \times 0.03) \mathrm{cm}$, in a reaction chamber containing $50 \mathrm{~mL}$ of test solution. Temperature changes were measured at one minute interval using a thermometer with a precision of $0.01 \mathrm{~K}$. The temperature increased slowly at first then rapidly and attained a maximum temperature. Before falling the maximum temperature was recorded.

Percentage inhibition efficiency was calculated as

$$
\eta=\frac{100\left(\mathrm{RN}_{\text {free }}-\mathrm{RN}_{i}\right)}{\mathrm{RN}_{\text {free }}},
$$

where $\mathrm{RN}_{i}$ and $\mathrm{RN}_{\text {free }}$ are the reaction number in the presence and absence of inhibitors, respectively and $\mathrm{RN}$ $(\mathrm{K} / \mathrm{min})$ is defined as

$$
\mathrm{RN}=\frac{(T m-T o)}{t},
$$

where $T m$ and $T o$ are the maximum and initial temperature, respectively, and $t$ is the time required to reach the maximum temperature.

\section{Result and Discussion}

Values of mass loss and percentage inhibition efficiency $(\eta)$ at different concentrations of acid and inhibitor are given in Tables 1 and 2. It is observed that the inhibition efficiency increases with increasing acid and inhibitor concentration. All the inhibitors reduce the corrosion rate to a significant extent. The maximum efficiencies are obtained at $2 \mathrm{~N}$ acid concentration. The inhibitor shows efficiencies in the range from $61.72 \%$ to a maximum $98.27 \%$ for acetone extract (Table 2). Corrosion is substantially reduced in the case of $0.60 \%$ inhibitor concentration of acetone, petroleum ether, and methanol extract in $2 \mathrm{~N}$ hydrochloric acid solution (Table 2). Inhibition efficiency values were also determined by using thermometric techniques. Temperature change for aluminium in $3 \mathrm{~N}, 4 \mathrm{~N}$, and $5 \mathrm{~N}$ hydrochloric acid solution was recorded at various inhibitor concentration. However, no significant temperature changes were recorded in acid concentration of $1 \mathrm{~N}$ and $2 \mathrm{~N}$ hydrochloric acid solution. Therefore, use of the thermometric method was restricted to $3 \mathrm{~N}-5 \mathrm{~N}$ hydrochloric acid solutions. The results summarized in Figures 3, 4, and 5 are in broad agreement with 
TABLE 1: Inhibition efficiency, corrosion rate, and surface coverage for aluminium in $0.1 \mathrm{~N}$ and $0.5 \mathrm{~N}$ hydrochloric acid solution with given inhibitor addition for $24 \mathrm{~h}$ at $298 \pm 1 \mathrm{~K}$.

\begin{tabular}{|c|c|c|c|c|c|c|}
\hline Conc. Inh. (\%) & $\begin{array}{l}\text { Inhibition efficiency } \\
\qquad(0.1 \mathrm{~N})\end{array}$ & $\begin{array}{l}\text { Corrosion rate } \\
\qquad(0.1 \mathrm{~N})\end{array}$ & $\begin{array}{l}\text { Surface coverage } \\
(0.1 \mathrm{~N})\end{array}$ & $\begin{array}{l}\text { Inhibition efficiency } \\
\qquad(0.5 \mathrm{~N})\end{array}$ & $\begin{array}{l}\text { Corrosion rate } \\
\qquad(0.5 \mathrm{~N})\end{array}$ & $\begin{array}{c}\text { Surface coverage } \\
(0.5 \mathrm{~N})\end{array}$ \\
\hline \multicolumn{7}{|l|}{ Pet. Ether extract } \\
\hline 0.12 & 14.02 & 13.27 & 0.1402 & 24.25 & 29.27 & 0.2425 \\
\hline 0.24 & 19.63 & 12.40 & 0.1963 & 27.61 & 27.97 & 0.2761 \\
\hline 0.36 & 35.51 & 9.95 & 0.3551 & 35.82 & 24.80 & 0.3582 \\
\hline 0.48 & 40.19 & 9.23 & 0.4019 & 42.54 & 22.21 & 0.4254 \\
\hline 0.60 & 44.86 & 8.51 & 0.4486 & 48.13 & 20.04 & 0.4813 \\
\hline \multicolumn{7}{|l|}{ Acetone extract } \\
\hline 0.12 & 12.15 & 13.55 & 0.1215 & 19.03 & 31.29 & 0.1903 \\
\hline 0.24 & 22.43 & 11.97 & 0.2243 & 24.63 & 29.13 & 0.2463 \\
\hline 0.36 & 41.12 & 9.08 & 0.4112 & 30.60 & 26.82 & 0.3060 \\
\hline 0.48 & 45.79 & 8.36 & 0.4579 & 39.18 & 23.50 & 0.3918 \\
\hline 0.60 & 51.40 & 7.50 & 0.5140 & 53.73 & 17.88 & 0.5373 \\
\hline \multicolumn{7}{|l|}{ Methanol extract } \\
\hline 0.12 & 10.28 & 13.84 & 0.1028 & 18.28 & 31.58 & 0.1828 \\
\hline 0.24 & 16.82 & 12.83 & 0.1682 & 22.76 & 29.85 & 0.2276 \\
\hline 0.36 & 23.36 & 11.82 & 0.2336 & 26.12 & 28.55 & 0.2612 \\
\hline 0.48 & 29.91 & 10.81 & 0.2991 & 36.19 & 24.66 & 0.3619 \\
\hline 0.60 & 42.06 & 8.94 & 0.4206 & 47.76 & 20.18 & 0.4776 \\
\hline
\end{tabular}

TABLE 2: Inhibition efficiency, corrosion rate, and surface coverage for aluminium in $1 \mathrm{~N}$ and $2 \mathrm{~N}$ hydrochloric acid solution with given inhibitor addition for $24 \mathrm{~h}$ at $298 \pm 1 \mathrm{~K}$.

\begin{tabular}{|c|c|c|c|c|c|c|}
\hline Conc. Inh (\%) & $\begin{array}{l}\text { Inhibition efficiency } \\
\qquad(1 \mathrm{~N})\end{array}$ & $\begin{array}{c}\text { Corrosion rate } \\
(1 \mathrm{~N})\end{array}$ & $\begin{array}{c}\text { Surface coverage } \\
(1 \mathrm{~N})\end{array}$ & $\begin{array}{l}\text { Inhibition efficiency } \\
\qquad(2 \mathrm{~N})\end{array}$ & $\begin{array}{l}\text { Corrosion rate } \\
(2 \mathrm{~N})\end{array}$ & $\begin{array}{c}\text { Surface coverage } \\
\qquad(2 \mathrm{~N})\end{array}$ \\
\hline \multicolumn{7}{|c|}{ Pet. Ether extract } \\
\hline 0.12 & 29.44 & 50.47 & 0.2944 & 88.61 & 30.43 & 0.8861 \\
\hline 0.24 & 44.96 & 39.37 & 0.4496 & 88.77 & 29.99 & 0.8877 \\
\hline 0.36 & 46.57 & 38.21 & 0.4657 & 89.74 & 27.40 & 0.8974 \\
\hline 0.48 & 55.61 & 35.33 & 0.5561 & 91.68 & 22.21 & 0.9168 \\
\hline 0.60 & 54.03 & 32.88 & 0.5403 & 92.66 & 19.61 & 0.9266 \\
\hline \multicolumn{7}{|l|}{ Acetone extract } \\
\hline 0.12 & 25.81 & 53.06 & 0.2581 & 61.72 & 102.24 & 0.6172 \\
\hline 0.24 & 28.63 & 51.05 & 0.2863 & 64.36 & 95.17 & 0.6436 \\
\hline 0.36 & 39.11 & 43.55 & 0.3911 & 91.63 & 22.35 & 0.9163 \\
\hline 0.48 & 57.86 & 30.14 & 0.5786 & 93.30 & 17.88 & 0.9330 \\
\hline 0.60 & 73.39 & 19.03 & 0.7339 & 98.27 & 4.61 & 0.9827 \\
\hline \multicolumn{7}{|c|}{ Methanol extract } \\
\hline 0.12 & 11.90 & 63.01 & 0.1190 & 49.30 & 135.40 & 0.4930 \\
\hline 0.24 & 20.28 & 57.10 & 0.2028 & 54.27 & 122.14 & 0.5427 \\
\hline 0.36 & 34.68 & 46.72 & 0.3468 & 58.80 & 110.02 & 0.5880 \\
\hline 0.48 & 38.51 & 50.47 & 0.3851 & 62.09 & 101.23 & 0.6209 \\
\hline 0.60 & 49.60 & 36.05 & 0.4960 & 67.12 & 87.82 & 0.6712 \\
\hline
\end{tabular}

those obtained from mass loss measurement. In particular inhibition efficiency increases with increasing concentration of both acid and inhibitor. The variation of reaction number with inhibitor concentrations, presented graphically, shows essentially linear behavior with the negative slop indicating that the reaction number decreases with increasing inhibitor concentration.
Generally, the adsorption of organic molecules on metal surface involves oxygen, nitrogen, and sulphur atoms. In the case of plant extract of Solanum surrattence, oxygen and nitrogen atoms are responsible for the adsorption. This process may block the active sites of metal surface, hence decreasing in corrosion rates. The $\mathrm{N}$ atom of the plant extract acts as reaction center because of its higher electron density, 


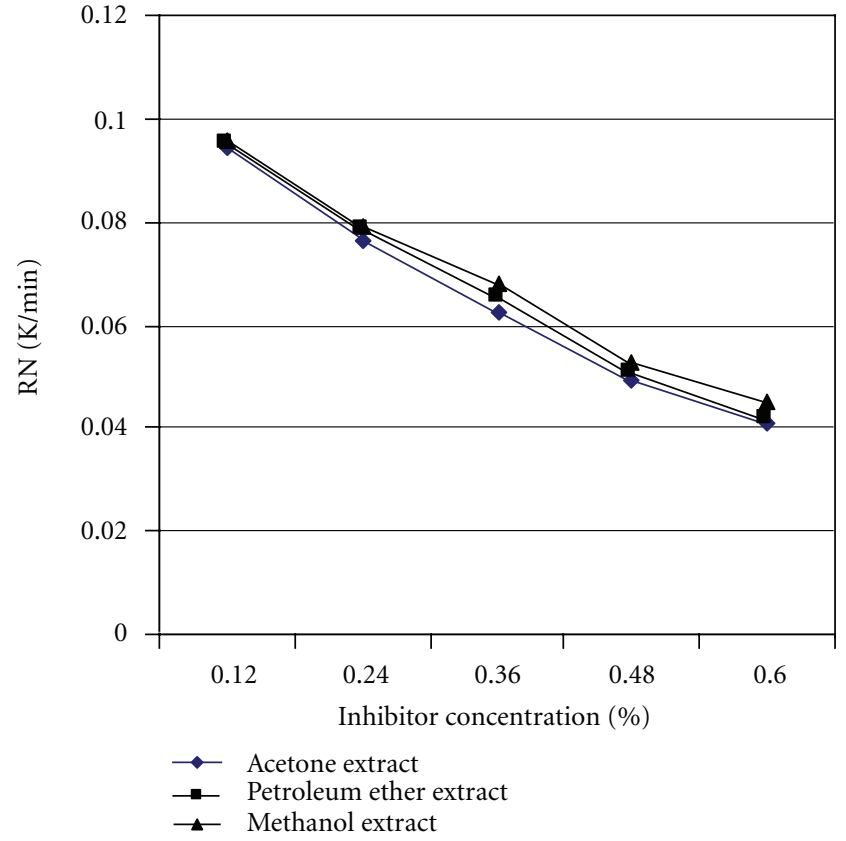

FIGURE 3: Variation of reaction number (RN) with inhibitor concentration for aluminium in $3 \mathrm{~N}$ hydrochloric acid solution.

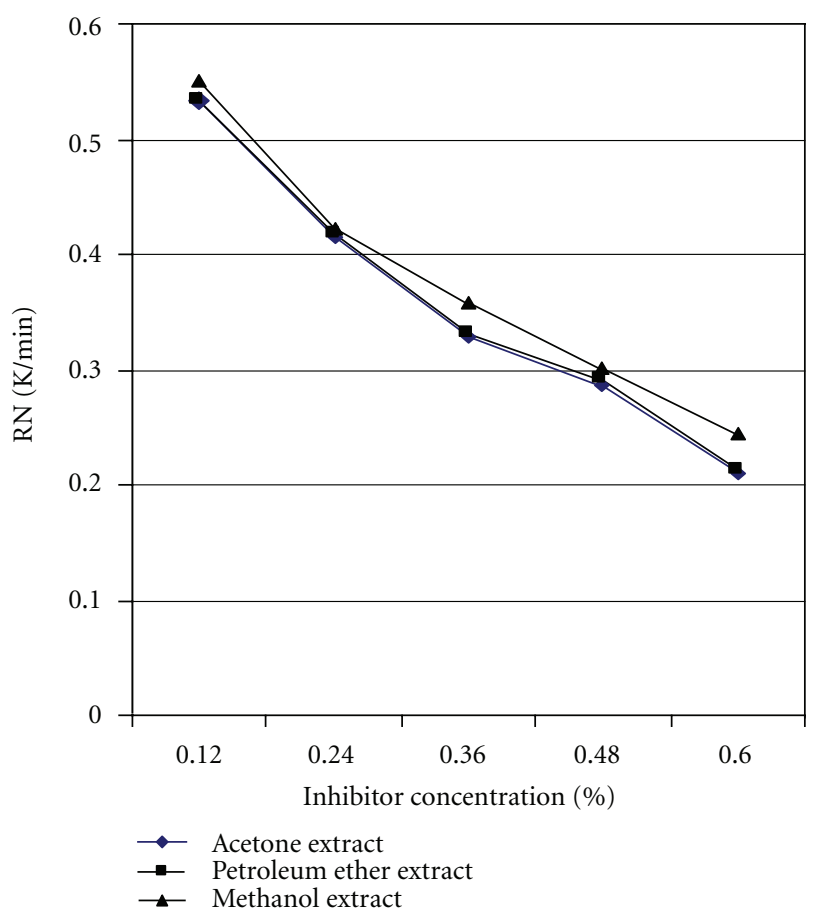

FIGURE 4: Variation of reaction number (RN) with inhibitor concentration for aluminium in $4 \mathrm{~N}$ hydrochloric acid solution.

resulting in the formation of a monolayer on the metal surface. It has been observed that the inhibition efficiency increases as the acid concentration increases. This may be because the inhibitor ionizes more easily under more acidic solution and is more easily adsorbed on the metal surface, hence increasing the inhibition efficiency.

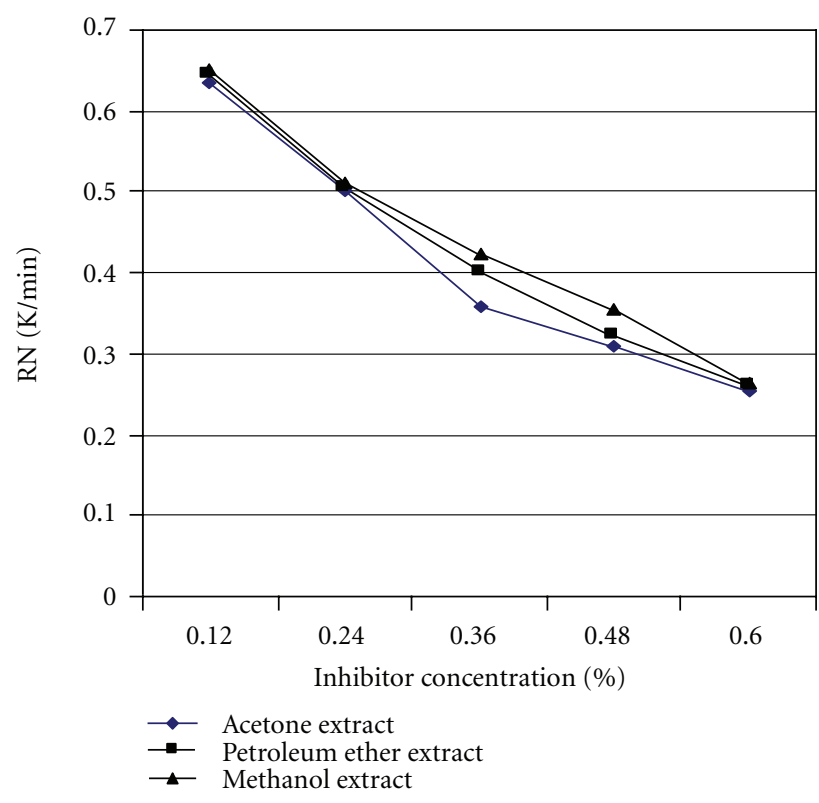

FIGURE 5: Variation of reaction number (RN) with inhibitor concentration for aluminium in $5 \mathrm{~N}$ hydrochloric acid solution.

All the Tables and Figures 3, 4, 5, 6, and 7 show that the inhibition efficiency of plant extract in different solvents (i.e., acetone, petroleum ether, and methanol) has been found to be in the following order:

$$
\text { acetone }>\text { petroleum ether }>\text { methanol. }
$$

The plant extract in acetone solvent shows the maximum inhibition efficiency which is probably due to the strong adsorption by oxygen of carbonyl group of acetone on metal surface.

Adsorption plays an important role in the inhibition of metallic corrosion by inhibitors. Many investigators have used the Langmuir adsorption isotherm to study inhibitors characteristics [11] assuming that the inhibitors adsorbed on the metal surface decrease the surface area available for the cathodic and anodic reactions to take place.

Langmuir adsorption isotherm

$$
\log \left[\frac{\theta}{1-\theta}\right]=\log A+\log C-\left(\frac{\theta}{2.3 \mathrm{RT}}\right)
$$

should give a straight line of unit gradient for the plot of $\log [\theta /(1-\theta)]$ versus $\log C$ where $\theta$ is surface coverage, $A$ is a temperature-independent constant, and $C$ is a concentration of the inhibitor. The corresponding plot (Figures 6 and 7) is linear, but the gradients are not equal to unity as would be expected for the Langmuir adsorption isotherm equation. This deviation from the unity may be explained on the basis of the interaction among the adsorbed species on the metal surface.

\section{Conclusion}

The study of plant extract in different solvents has shown them to be effective inhibitors of the corrosion of aluminium 


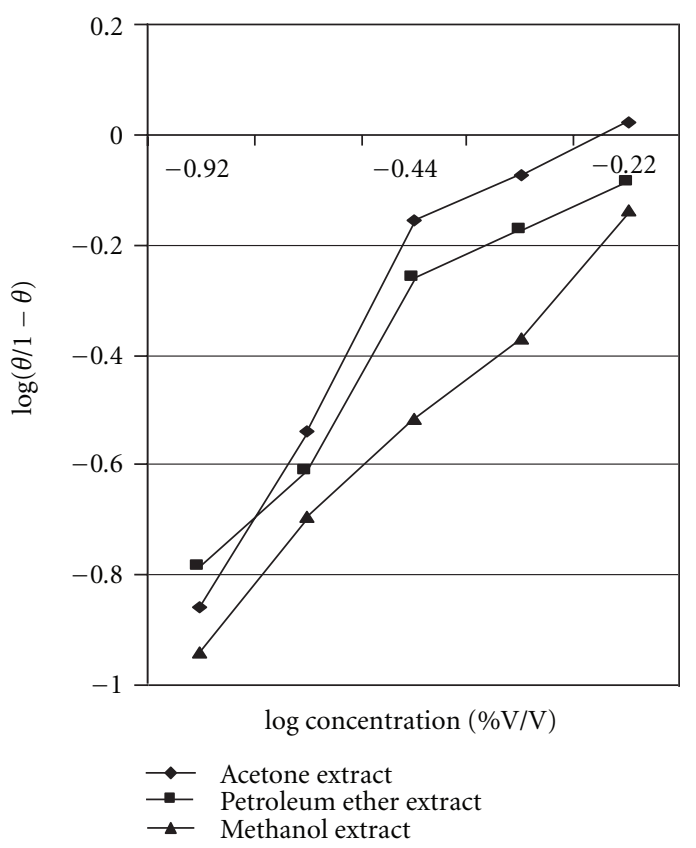

FIGURE 6: Langmuir adsorption isotherm for aluminium in $0.1 \mathrm{~N}$ Hydrochloric acid solution with inhibitor additions.

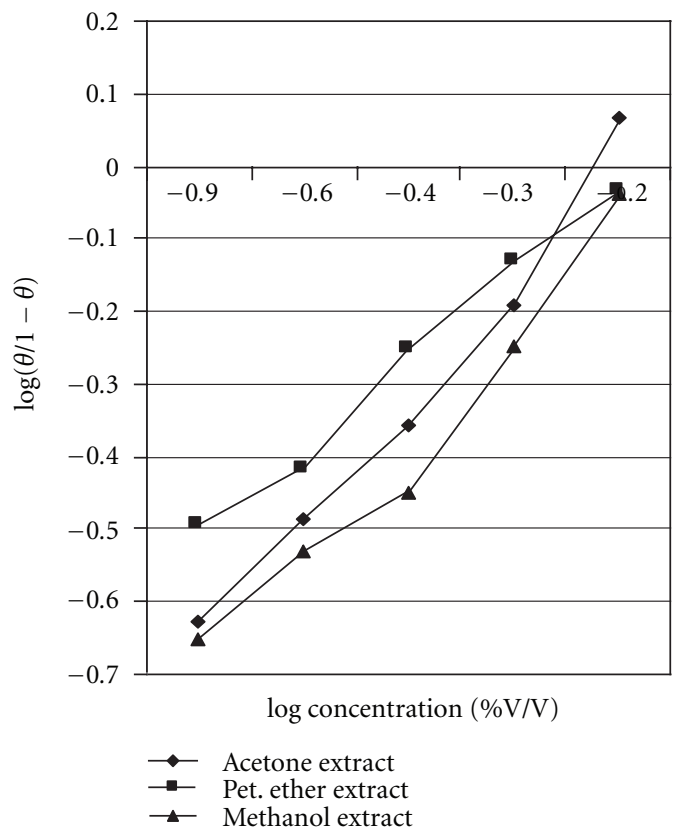

FIgURE 7: Langmuir adsorption isotherm for aluminium in $0.5 \mathrm{~N}$ Hydrochloric acid solution with inhibitor additions.

in hydrochloric acid solution. Both mass loss and thermometric determinations have shown that the inhibition efficiency increases with increasing inhibitor concentration over the range $0.12 \%-0.60 \%$ and with increasing acid concentration within the range $0.1 \mathrm{~N}$ to $5 \mathrm{~N}$ hydrochloric acid solution. Adsorption of these compounds on aluminium obeyed Langmuir adsorption isotherm. It is concluded that the plant extract of Solanum surrattence is a good corrosion inhibitor for aluminium in acidic solution. This type of inhibitor is ecofriendly, biodegradable, and less toxic therefore these types of inhibitors can be used to replace toxic chemicals.

\section{References}

[1] A. Y. El-Etre, "Inhibition of aluminum corrosion using Opuntia extract," Corrosion Science, vol. 45, no. 11, pp. 24852495, 2003.

[2] E. Chaieb, A. Bouyanzer, B. Hammouti, and M. Benkaddour, "Inhibition of the corrosion of steel in $1 \mathrm{M} \mathrm{HCl}$ by eugenol derivatives," Applied Surface Science, vol. 246, no. 1-3, pp. 199206, 2005.

[3] M. K. Sharma, P. Arora, S. Kumar, S. P. Mathur, and R. Ratnani, "Inhibitive effect of Prosopis cineraria on mild steel in acidic media," Corrosion Engineering Science and Technology, vol. 43, no. 3, pp. 213-218, 2008.

[4] M. K. Sharma, S. Kumar, R. Ratnani, and S. P. Mathur, "Corrosion inhibition of Aluminium by extracts of Prosopis cineraria in acidic media," Bulletin of Electrochemistry, vol. 22, no. 2, pp. 69-74, 2006.

[5] G. Kusano, J. Beisler, and Y. Sato, "Steroidal constituents of Solanum xanthocarpum," Phytochemistry, vol. 12, no. 2, pp. 397-401, 1973.

[6] S. V. Tupkari, A. N. Saoji, and V. K. Deshmukh, "Phytochemical study of Solanum xanthocarpum," Planta Medica, vol. 22, no. 2, pp. 184-187, 1972.

[7] S. Siddiqui, S. Faizi, and B. S. Siddiqui, "Studies in the chemical constituents of fresh barries of Solanum xanthocarpum schard and wendle," Journal of Chemical Socity Pakistan, vol. 5, no. 2, pp. 99-102, 1983.

[8] P. Dubey and P. C. Gupta, "A new flavonol glycoside from the flowers of Solanum xanthocarpum," Phytochemistry, vol. 17, no. 12 , pp. 2138-2140, 1978.

[9] The Usefull Plants of India, Publication and Information Directorate CSIR, New Delhi, India, 1986.

[10] T. Jain, R. Chowdhary, P. Arora, and S. P. Mathur, "Corrosion inhibition of aluminum in hydrochloric acid solutions by peepal (Ficus Religeosa) extracts," Bulletin of Electrochemistry, vol. 21, no. 1, pp. 23-27, 2005.

[11] A. Bansiwal, P. Anthony, and S. P. Mathur, "Inhibitive effect of some Schiff bases on corrosion of aluminium in hydrochloric acid solutions," British Corrosion Journal, vol. 35, no. 4, pp. 301-303, 2000. 

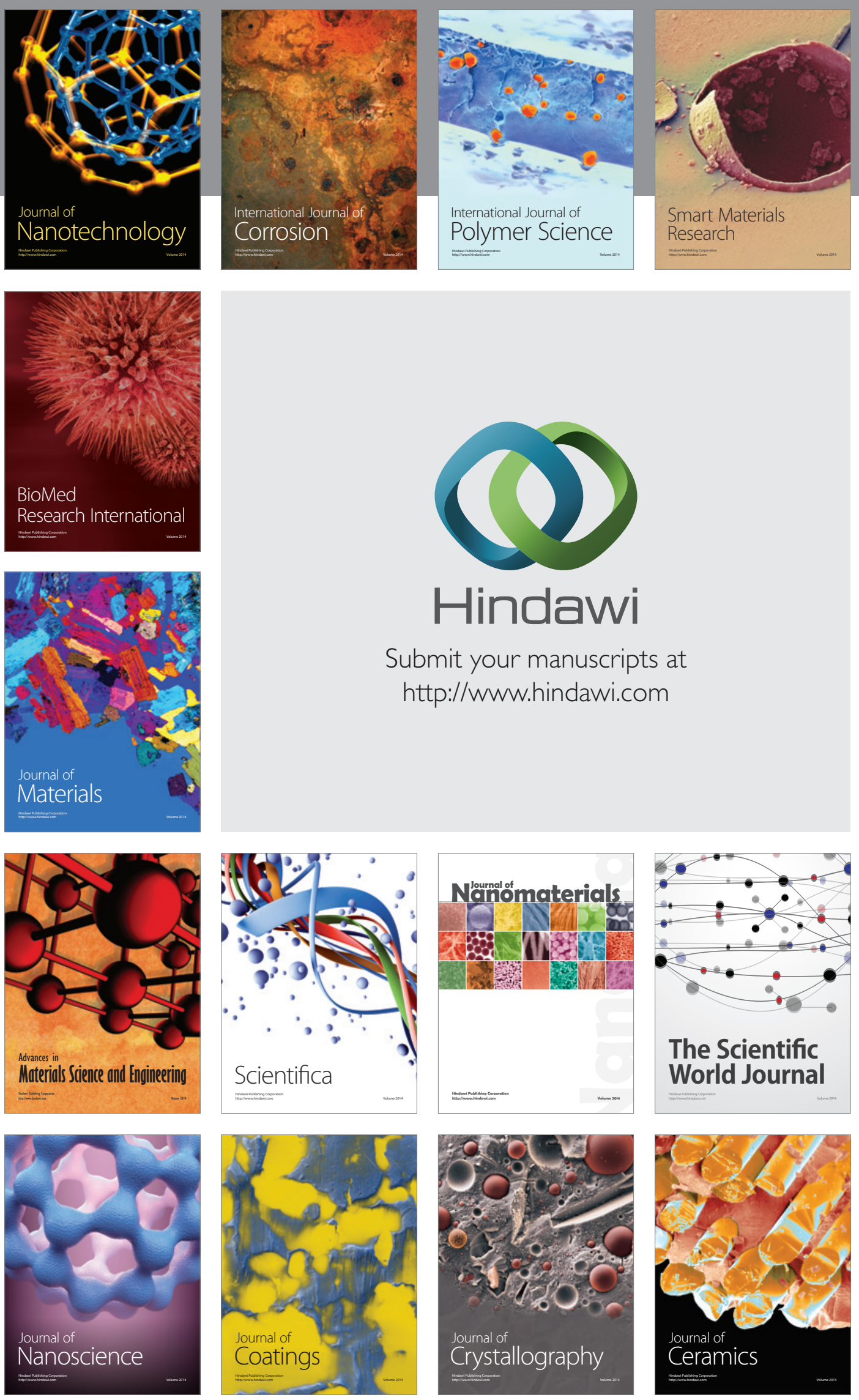

The Scientific World Journal

Submit your manuscripts at

http://www.hindawi.com

\section{World Journal}

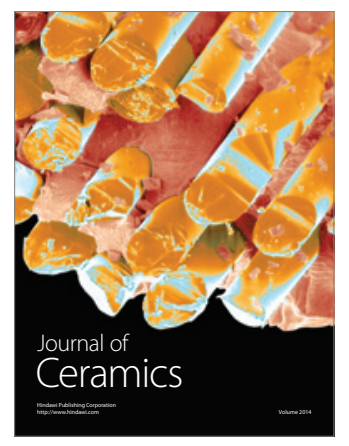

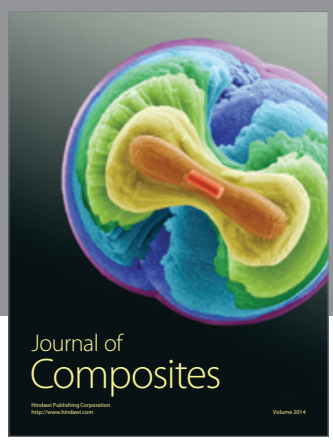
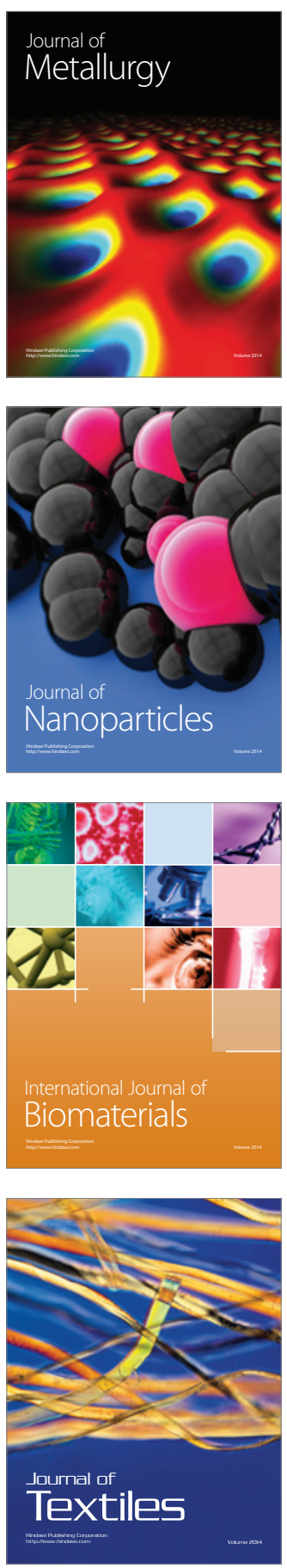